\title{
Magnetization Transfer Magnetic Resonance Imaging of the Brain, Spinal Cord, and Optic Nerve
}

\author{
Massimo Filippi and Maria A. Rocca \\ Neuroimaging Research Unit, Department of Neurology, Scientific Institute and University Hospital San Raffaele, Milan, Italy
}

\begin{abstract}
Summary: Magnetic resonance imaging is highly sensitive in revealing CNS abnormalities associated with several neurological conditions, but lacks specificity for their pathological substrates. In addition, MRI does not allow evaluation of the presence and extent of damage in regions that appear normal on conventional MRI sequences and that postmortem studies have shown to be affected by pathology. Quantitative MR-based techniques with increased pathological specificity to the heterogeneous substrates of CNS pathology have the potential to overcome such limitations. Among these techniques, one of the most extensively used for the assessment of CNS disorders is magnetization transfer MRI (MT-MRI). The application of this
\end{abstract}

technique for the assessment of damage in macroscopic lesions, in normal-appearing white and gray matter, and in the spinal cord and optic nerve of patients with several neurological conditions is providing important in vivo information-dramatically improving our understanding of the factors associated with the appearance of clinical symptoms and the accumulation of irreversible disability. MT-MRI also has the potential to contribute to the diagnostic evaluation of several neurological conditions and to improve our ability to monitor treatment efficacy in experimental trials. Key Words: Magnetic resonance imaging, magnetization transfer imaging, brain, spinal cord, optic nerve, demyelinating conditions, neurodegenerative conditions.

\section{INTRODUCTION}

In many neurological conditions, MRI has proved to be a sensitive tool for detecting CNS abnormalities and their changes over time. Despite such a high sensitivity, conventional MRI (i.e., dual-echo, fast fluid attenuated inversion recovery and T1-weighted scans with or without paramagnetic contrast) does not provide an accurate estimate of the extent and nature of the associated tissue damage. Quantitative MR-based techniques with increased pathological specificity to the heterogeneous substrates of CNS pathology have the potential to overcome such limitations. Among such techniques, magnetization transfer MRI (MT-MRI) has been one of the most extensively applied for the assessment of CNS disorders.

The present review summarizes the major contributions of MT-MRI for the in vivo monitoring of various CNS diseases. Because MT-MRI has been applied primarily to improve our understanding of the pathophysiology of multiple sclerosis (MS), a special focus is de-

Address correspondence and reprint requests to: Massimo Filippi, M.D., Neuroimaging Research Unit Department of Neurology, Scientific Institute and University Ospedale San Raffaele, Via Olgettina, 60, 20132 Milan, Italy. E-mail: m.filippi@hsr.it. voted to this condition and to allied white matter (WM) disorders.

\section{BASIC PRINCIPLES OF MT-MRI}

MT contrast results from the interactions between the protons in free fluid in a tissue and those protons bound in macromolecules. ${ }^{1}$ Although the magnetization from these macromolecules cannot be observed directly, proton magnetization is in constant exchange between the free fluid and the macromolecules, and so magnetization saturation and relaxation within the macromolecule affect the observable signal from the free water. ${ }^{2}$

MT contrast is achieved by applying a radio frequency (RF) power only to the proton magnetization of the macromolecules. Because, in brain tissue, the free water protons and macromolecular protons have the same central resonance frequency but very different line widths, this can be achieved by shifting the frequency of the saturating RF pulses to one side of the free water resonance line. ${ }^{3}$ The RF pulse frequency offset is chosen to minimize direct saturation of the free pool within the constraint of remaining sufficiently small that it is not out of the frequency range of the broad resonance line of the macromolecular spins. 
The most general description of the MT effect uses data acquired at a range of saturating powers and offsets, and models the system as two or more compartments. ${ }^{4}$ This allows both the relaxation rates of the pools and their relative proportions to be determined. More simply, the MT effect can be characterized by a nonspecific pseudo rate constant $\left(k_{\mathrm{f}}\right)$ for the MT process. Note that $k_{\mathrm{f}}$ includes both chemical exchange and dipolar coupling between bound and free protons. The $k_{\mathrm{f}}$ can be found by measuring the free water signal twice: in the presence and in the absence of the MT saturating pulses. The free water relaxation rate in the presence of the saturating pulses $\left(R_{1 \text { sat }}\right)$ must also be measured, in which case

$$
k_{\mathrm{f}}=R_{1 \mathrm{sat}} \frac{\left(M_{0}-M_{\mathrm{S}}\right)}{M_{0}},
$$

where $M_{0}$ is the magnitude of the free water proton signal in the absence of the off-resonance saturating pulses, and $M_{\mathrm{S}}$ is the magnitude of the free water proton signal with the off-resonance saturating pulses applied. Note, however, that the above equation is strictly valid only in the case of perfect saturation of the bound pool, a condition that cannot be achieved in vivo on with clinical scanners.

If the rate constant is not specifically of interest, then one can calculate the MT ratio (MTR), a simple measure of MT effects:

$$
\text { MTR }=\frac{\left(M_{0}-M_{\mathrm{S}}\right)}{M_{0}} \times 100 .
$$

A low MT ratio (MTR) indicates a reduced capacity of free water to exchange magnetization with the brain tissue matrix with which the water comes into intimate contact. For example, in CSF, where there is almost a complete absence of macromolecules, no exchange can occur, the observable signal is unaffected by the saturation pulses, and the MTR approaches zero. In healthy brain tissue, where $M_{\mathrm{S}}$ drops significantly below $M_{0}$ as the saturated magnetization is transferred to the observable water, an MTR of up to $40-50 \%$ may be seen, depending on the pulse sequence used.

Although at present nearly all clinical MT-MRI studies are based on MTR measurements, the reduction of the MT phenomenon to a single MTR value has limited the interpretation of the results and the ability to achieve an optimal standardization of MTR measurements across multiple centers. MT-MRI uses off-resonance RF pulses to create contrast, and the MTR values obtained strongly depend on the offset frequency, bandwidth, and average power of the pulses. Differences among centers can be minimized by standardizing the pulse sequence implementation and choice of parameters - although, where multiple scanner types are to be used, this may lead to the use of a lowest common denominator sequence rather than to an optimal one.

\section{ANALYSIS OF MT-MR IMAGES}

Once MTR maps have been produced, several approaches can be adopted to analyze disease-related abnormalities on these maps.

1. Region of interest analysis of specific tissues. The region of interest (ROI) approach allows the study of individual lesions and discrete areas of the normal-appearing white matter (NAWM) and gray matter (GM).

2. Analysis of average MTR. An approach based on average MTR of T2-visible or T1-visible lesions (or both) allows obtaining information about the severity of tissue damage of the overall lesion population or of lesions with more severe tissue damage.

3. Contour plotting of MTR. The contour-plotting approach displays the MTR values as an overlay on MR images. ${ }^{5,6}$ In this way, it is possible to detect gradients and boundaries of abnormal MTR that are too subtle to be detected by conventional reading of the MTR maps.

4. Histogram analysis of large portions of brain or cord tissues. The histogram approach encompasses both microscopic and macroscopic lesion burdens in the examined tissue. ${ }^{7}$ For each histogram, several parameters can be calculated. ${ }^{7}$ The most widely used include the height and position of the histogram peak (i.e., the most common MTR value in the brain) and the average MTR. MTR histograms can be obtained for the whole brain; for specific regions of the brain (e.g., NAWM, GM, frontal lobe, cerebellum, and brainstem), which can be segmented according to standard neuroanatomical references; and for the cervical cord. MTR histogram analysis is a highly automated technique and, as a consequence, intrarater, interrater, and scan-rescan variabilities of MTR histogram-derived metrics are low., 8

5. Voxel-based statistical analysis of MTR images. The voxel-based approach, which uses standardized anatomical spaces and a voxel-by-voxel analysis, allows the investigator to obtain an overall assessment of macroscopic and microscopic damage from the entire brain or from specific brain tissues, such as the GM, while preserving spatial information of lesion location (which is lost with histogram analysis) and without a priori knowledge about lesion distribution. ${ }^{10,11}$

\section{MT-MRI IN MS}

Studies of individual lesions indicate that MT-MRI is a valuable instrument for grading the severity of intrinsic lesion damage. Homogeneously enhancing lesions, which may represent new active lesions, have significantly higher MTR values than do ring-enhancing lesions, ${ }^{12-15}$ which may represent old, reactivated lesions. The duration of enhancement is also associated with different degrees of MTR changes in new MS lesions: lesions enhancing on at least two consecutive monthly scans have lower MTR than those enhancing on a single 
scan, ${ }^{16}$ suggesting that a longer enhancement in MS lesions may be related to a more severe tissue damage.

That a less-damaged blood-brain barrier (BBB) is associated with milder tissue damage is also indicated by the demonstration that new lesions enhancing after the injection of a standard dose of gadolinium (Gd) have significantly lower MTR values than those enhancing only after a triple dose ${ }^{17}$ and by the demonstration that large enhancing lesions tend to have greater MTR reductions than do smaller lesions. ${ }^{12}$ On average, MTR drops dramatically when the lesions start to enhance and may show a partial or complete recovery in the subsequent 1-6 six months.

The relatively good preservation of axons that is usual in acute MS lesions ${ }^{18}$ and the rapid and marked increase of the MTR are consistent with demyelination and subsequent remyelination, but not axonal loss. Nevertheless, edema and its subsequent resolution may also give rise to the observed pattern of MTR behavior, due to the diluting effect of extratissue water, causing an initial decreased MTR with vasogenic edema, followed by recovery of MTR with resolution of edema. It seems unlikely, however, that edema alone is sufficient to explain these findings, because edema in the absence of demyelination results in only modest MTR reductions. ${ }^{13,19}$ The effect of gliosis on MTR is likely to be marginal, if any: a postmortem study was unable to detect any correlation between MTR and the severity of MS lesion and NAWM gliosis. ${ }^{20}$ The application of an MT pulse to postcontrast T1-weighted images has been shown to increase the sensitivity of postcontrast T1-weighted scans for detecting active MS lesions. $^{21}$

Established MS lesions have a wide range of MTR values. ${ }^{22}$ Hypointense lesions, which are characterized by severe axonal loss and demyelination, ${ }^{23}$ have lower MTR values than do lesions that are isointense to NAWM on T1-weighted scans. ${ }^{14,24}$ MTR of these T1hypointense lesions has been found to be inversely correlated with their degree of hypointensity. ${ }^{14}$ Decreased MTR has also been found in NAWM areas that are adjacent to focal T2-weighted MS lesions ${ }^{25-27}$ and in WM areas characterized by subtle and diffuse signal intensity changes on T2-weighted MR images (referred as "dirty-appearing" WM). ${ }^{28}$ MTR progressively increased with distance from MS lesions to the cortical GM, and MTR was lower for patients with more disabling MS courses. ${ }^{25}$ These findings suggest that the actual size of MS lesions is greater than that visible on T2-weighted images and that the demyelinating penumbra detected by MT-MRI might be relevant in determining a patient's disability.

The relative proportion of $\mathrm{T} 2$-visible lesions with low MTR values is likely to contribute to the presence and accumulation of disability in patients with MS. Average lesion MTR has indeed been found to be lower in pa- tients with relapsing remitting (RR) MS than in those with clinically isolated syndromes (CIS) suggestive of $\mathrm{MS}^{24,29}$ or in those with benign MS. ${ }^{30}$ Low average lesion MTR has also been found in patients with secondary progressive (SP) and primary progressive (PP) MS. ${ }^{31}$ Furthermore, a 3-year follow-up study showed that newly formed lesions from patients with SPMS have a more severe MTR deterioration than those from patients with mildly disabling RRMS. ${ }^{32}$ Patients with cognitive impairment have a significantly lower average lesion MTR than do those without, but average lesion MTR was found to explain only $35 \%$ of the total variance in neuropsychological test performance. ${ }^{33}$

Average lesion MTR percentage change over a year was found to be an independent predictor of accumulation of disability in the subsequent 7 years in a cohort of patients with CIS, RRMS, and SPMS. ${ }^{34}$ The only partial correlation found was between the degree of intrinsic lesion damage, measured using average lesion MTR, and the clinical manifestations of MS; this might be due, on the one hand, to the variable extent of tissue damage outside T2-visible lesions or, on the other, to the fact that intrinsic lesion damage can induce adaptive cortical changes, ${ }^{35,36}$ which in turn have the potential to limit the clinical consequences of subcortical WM damage. ${ }^{36}$

\section{MT-MRI OF NORMAL-APPEARING BRAIN TISSUE AND NAWM}

Postmortem studies have shown that abnormalities can be detected in NAWM from patients with MS. ${ }^{37,38}$ These abnormalities include diffuse astrocytic hyperplasia, patchy edema and perivascular cellular infiltration. In addition, Arstila et al. ${ }^{37}$ described abnormally thin myelin in biopsies from NAWM of MS patients, and signs of axonal damage in MS NAWM have also been detected. ${ }^{39,40}$ Such pathological abnormalities modify the relative proportions of mobile and immobile protons of the diseased tissue, and so it is not surprising that MT-MRI is able to show microscopic damage in NAWM that conventional imaging fails to detect. ${ }^{25-27}$

Decreased MTR values have been found, using ROI and histogram analysis, in normal-appearing brain tissue (NABT) and NAWM of MS patients, ${ }^{24,29,30,41-47}$ which can precede new lesion formation. ${ }^{48-51}$ NABT and NAWM MTR abnormalities have been detected in patients with CIS suggestive of MS, ${ }^{29,44,46}$ increase progressively in early RRMS ${ }^{45}$ and early PPMS ${ }^{47}$ and are more pronounced in SPMS and PPMS patients than in patients with the other main disease phenotypes. ${ }^{24,31,41-43}$ Benign MS patients had NABT MTR values significantly higher than those of early RRMS patients. ${ }^{30}$ NABT MTR was found to be normal in patients with early-onset MS. ${ }^{52}$

In agreement with the notion that NABT and NAWM 
MTR values differ in the various MS phenotypes, decreased MTR values have been associated with the severity of locomotor disability ${ }^{11,42,53-55}$ and cognitive impairment, ${ }^{33,56-59}$ but no correlation has been found with the severity of fatigue. ${ }^{60}$ Evidence also suggests that NABT MTR may predict subsequent disease evolution. A significant decline of NABT MTR over time has been shown to occur at a faster rate in patients with SPMS than in patients with other clinical phenotypes. ${ }^{61}$ A relationship between the extent of NABT MTR changes in CIS patients and the subsequent evolution to definite MS has been suggested by some authors, ${ }^{29,50}$ but not by others. $^{62,63}$

In patients with established MS, two studies have shown that NAWM MTR predicts the accumulation of clinical disability over the subsequent 5 years. ${ }^{64,65}$ In MS patients, NABT MTR values are only partially correlated with the extent of macroscopic lesions and the severity of intrinsic lesion damage, ${ }^{31,66}$ which suggests that NABT changes do not reflect only wallerian degeneration of axons traversing large focal abnormalities. Indeed, a strong correlation has been found between NABT MTR and brain volume, ${ }^{66}$ suggesting that NABT damage is involved in determining irreversible tissue loss in MS.

More recently, in patients with RRMS ${ }^{35}$ and PPMS, ${ }^{67}$ moderate to strong correlations have also been found between the severity of structural changes of the NABT (as measured using MT-MRI) and the relative activations of several cortical areas located in a widespread network for sensorimotor and multimodal integration, measured using functional MRI. This suggests that not only macroscopic MS lesions, but also subtle NABT changes can cause adaptive cortical reorganization with the potential to limit the functional consequences of MS-related structural damage.

\section{GRAY MATTER}

Postmortem studies have shown that MS pathology does not spare cerebral GM. ${ }^{68-71}$ Consistent with this, several studies using different methodologies ( $\mathrm{ROI},{ }^{72}$ histogram, ${ }^{72-74}$ or voxel-based ${ }^{10,11}$ analysis) have shown reduced MTR values in the GM from patients with MS. Reduced GM MTR seems to be present in all MS clinical phenotypes, starting from the earliest clinical stage of the disease. $^{45-47}$

Such GM abnormalities, however, increase with disease duration; for example, they were found to be more pronounced in patients with PPMS or SPMS. ${ }^{31}$ The distribution of MTR abnormalities in the different brain GM structures still needs to be defined. In CIS patients with previous optic neuritis, voxel-based morphometry revealed that MTR changes were located mainly in the occipital cortex. ${ }^{75}$ In a recent study, a regional pattern of brain MTR decrease more evident in the basal ganglia was found in patients with early MS. ${ }^{10}$ By contrast, two other studies, ${ }^{76,77}$ of which one assessed thalamic MTR in early RRMS patients ${ }^{76}$ and the other measured MTR in caudate, putamen, globus pallidus and thalamus from RRMS and SPMS patients, ${ }^{77}$ found no significant difference between patients and controls. One of the studies, however, showed that the mean thalamic MTR became significantly lower in patients during follow-up. ${ }^{76}$

GM MTR changes have been found to correlate with physical disability ${ }^{47,73,74,78}$ and cognitive impairment, ${ }^{11}$ but no correlation with fatigue has emerged. ${ }^{79}$ GM MTR was also found to be an independent predictor of subsequent accumulation of disability in patients with MS monitored for 8 years. ${ }^{34}$ The moderate correlation found between the extent of intrinsic GM changes and WM pathology (both focal and what is called diffuse) ${ }^{47,72,73}$ suggests that MS-related GM abnormalities are only in part due to retrograde or trans-synaptic degeneration of GM neurons secondary to the damage of fibers tranversing diseased WM areas.

\section{MT-MRI FOR MONITORING TREATMENT EFFICACY}

An international consensus conference of the White Matter Study Group of the International Society for Magnetic Resonance in Medicine has recommended the use of MTMRI in the context of large-scale MS trials as an adjunctive measure to monitor disease evolution. ${ }^{80}$ As a consequence, ad hoc guidelines for implementing MT-MRI as a part of multicenter clinical trials have been produced. ${ }^{81}$

Several MS clinical trials have incorporated MT-MRI, with a view to assessing the effect of treatment on demyelination and axonal loss. To our knowledge, MTMRI has been used in phase II and phase III trials for RRMS (injectable and oral interferon beta-1a [IFN $\beta$-1a], $\operatorname{IFN} \beta-1 \mathrm{~b}$, and oral glatiramer acetate and intravenous methylprednisolone) and SPMS (IFN $\beta$-1b and intravenous immunoglobulins [IVIG]). Some of these studies were conducted at single centers with small numbers of patients ${ }^{82-85}$ and so were not confronted with problems of standardization of MT acquisition and postprocessing. In multicenter trials, ${ }^{86,87}$ MT-MRI acquisition has been limited to highly specialized MR centers and only subgroups of patients $(\sim 50-100$ per trial) have been studied using MT-MRI. Two of these studies with a baselineversus-treatment design have shown that treatment with IFN $\beta-1 b^{83}$ or IFN $\beta-1 a^{84}$ favorably modifies the recovery of MTR values that follows the cessation of Gd enhancement in newly formed lesions from RRMS patients.

These findings suggest that, in addition to its effects in reducing the formation of new lesions, IFN $\beta$ might also act by reducing tissue damage and promoting remyelination within those lesions that still form during therapy. By contrast, Richert et al. ${ }^{83}$ did not find any significant 
difference in the MTR values of NAWM ROIs or in parameters derived from whole-brain MTR histograms ${ }^{82}$ in a larger cohort of RRMS patients before or during IFN $\beta-1 \mathrm{~b}$ therapy. In the latter study, ${ }^{82}$ month-to-month fluctuations of the histogram peak height persisted during the treatment period despite the almost complete suppression of contrast-enhanced MRI activity.

A course of intravenous methylprednisolone ( $1 \mathrm{~g}$ daily $\times$ 3 days, followed by 12-day prednisone taper) did not modify favorably the changes of average lesion MTR and whole-brain MTR from 10 MS patients followed for 8 weeks. ${ }^{85}$ Two studies assessed MT changes in a relatively large cohort of IFN $\beta$ - 1 b-treated ${ }^{86}$ and IVIGtreated ${ }^{87}$ patients participating in multicenter placebocontrolled trials. Neither IFN $\beta$-1b nor IVIG showed an overall effect of worsening of MT-MRI measures, despite a dramatic effect of IFN $\beta-1 b$ on the formation of new lesions ${ }^{88}$ and of IVIG on the accumulation of brain atrophy. ${ }^{89}$

Taken together, these various findings confirm that MT-MRI has the potential to improve our ability to investigate the mechanisms of action of experimental treatments on the different aspects of MS pathology.

\section{MT-MRI STUDIES OF THE CERVICAL CORD AND OPTIC NERVES}

MT-MRI of the cervical cord and optic nerve presents technical difficulties, mainly because of the size of these two structures and their tendency to move during imaging. Nevertheless, recent work has shown it possible to acquire good-quality MT images of the cervical cord ${ }^{31,90-93}$ and optic nerve. $^{94-99}$

ROI analysis has revealed reduced MTR values in the cervical cord of MS patients, compared with healthy volunteers. ${ }^{90}$ Histogram analysis has demonstrated the absence of abnormalities in cord MTR histogram metrics of patients with RRMS, ${ }^{92}$ early-onset MS, ${ }^{52}$ and CIS. ${ }^{99}$ By contrast, cord MTR metrics are markedly reduced in patients with SPMS and PPMS. ${ }^{31}$ Cord MTR is only partially correlated with brain MTR, ${ }^{93}$ suggesting that MS pathology in the cord is not a mere reflection of brain pathology and that, as a consequence, measuring cord pathology might be a rewarding exercise in terms of understanding MS pathophysiology.

Two ROI-based studies reported abnormal MTR values in the optic nerve after an episode of acute optic neuritis, independent of the presence of T2-visible abnormalities. $^{94,95}$ MTR of the optic nerve has been found to be correlated with the visual evoked potential latency, ${ }^{94}$ and with the degree of visual function recovery ${ }^{96}$ after an acute episode of optic neuritis. In a 1-year follow-up study of patients with acute optic neuritis, Hickman et al. ${ }^{97}$ showed a progressive decline of average MTR of the affected optic nerve, which reached a nadir after $\sim 8$ months (despite rapid initial visual recovery). In confirmation of these findings, a progressive decrease of mean MTR values of the affected optic nerve was seen over time in 11 patients with a first episode of optic neuritis. ${ }^{98}$

\section{MT-MRI IN VARIANTS OF MS}

Among the variants of MS that have been described, only neuromyelitis optica and acute disseminated encephalomyelitis have been investigated with MT-MRI. Application of this technique for assessment of overall CNS damage in these patients has provided important pieces of information, which might contribute in their diagnostic work up (Table 1).

In patients with neuromyelitis optica, the MTR of

TABLE 1. MT-MRI Findings in CNS Compartments of White Matter Diseases and Other Conditions Associated With Significant White Matter Damage, in Comparison With Multiple Sclerosis

\begin{tabular}{|c|c|c|c|c|c|}
\hline \multirow[b]{2}{*}{ Disease } & \multicolumn{5}{|c|}{ Magnetization Transfer Ratio } \\
\hline & Lesion & NABT or NAWM & GM & Optic Nerve & Spinal Cord \\
\hline Neuromyelitis optica & Abnormal, $>$ MS & Normal & Abnormal & n.a. & Abnormal, $\approx \mathrm{MS}$ \\
\hline ADEM & Abnormal, $\approx \mathrm{MS}$ & Normal & n.a. & n.a. & Normal \\
\hline Neuro-SLE & Abnormal, $>$ MS & Abnormal, $\approx \mathrm{MS}$ & Abnormal & n.a. & n.a. \\
\hline Isolated myelitis & Abnormal, $>$ MS & Normal & Normal & n.a. & Abnormal \\
\hline Stroke & Abnormal & Abnormal & n.a. & n.a. & n.a. \\
\hline Migraine & Abnormal, $>$ MS & Normal & n.a. & n.a. & Normal \\
\hline CADASIL & Abnormal, $\approx \mathrm{MS}$ & Abnormal & n.a. & n.a. & Abnormal \\
\hline LHON & Abnormal, $\approx \mathrm{MS}$ & Normal & n.a. & Abnormal, $\approx \mathrm{MS}$ & n.a. \\
\hline Traumatic brain injury & Abnormal & Abnormal & n.a. & n.a. & n.a. \\
\hline Cerebrotendinous xanthomatosis & Abnormal & Abnormal & Abnormal & n.a. & n.a. \\
\hline Fabry's disease & Abnormal & Abnormal & n.a. & n.a. & n.a. \\
\hline
\end{tabular}

Abbreviations: ADEM, acute disseminated encephalomyelitis; CADASIL, cerebral autosomal dominant arteriopathy with subcortical infarcts and leukoencephalopathy; GM, gray matter; LHON, Leber's hereditary optic neuropathy; MS, multiple sclerosis; MT-MRI, magnetization transfer MRI; MTR, magnetization transfer ratio; n.a., not assessed; NABT, normal-appearing brain tissue; NAWM, normal-appearing white matter; SLE, systemic lupus erythematosus; $>$, higher than; $\approx$, similar to. 
focal nonspecific brain lesions is only mildly abnormalconsiderably less abnormal than in MS. MTR abnormalities in the NAWM have not been detected in patients with neuromyelitis optica. ${ }^{100}$ This is in contrast to findings with MS, and therefore the absence of MTR changes in the NAWM of patients with optic neuropathy and myelopathy increases the confidence in making a diagnosis of neuromyelitis optica. ${ }^{100}$ More recently, reduced GM-MTR values have been demonstrated in patients with neuromyelitis optica in comparison to healthy controls, ${ }^{101}$ challenging the classic notion of a sparing of the brain tissue in the course of neuromyelitis optica. Finally, similarly to MS, decreased cervical cord MTR has been found in these patients. ${ }^{100}$

Although the extent of intrinsic lesion damage, as measured with MT-MRI, is similar between patients with acute disseminated encephalomyelitis and those with MS, the NABT and spinal cord seem to be spared from MT-related pathological changes. ${ }^{102}$

\section{MT-MRI IN OTHER WM DISORDERS AND CONDITIONS ASSOCIATED WITH WM DAMAGE}

\section{Isolated myelitis}

In patients with isolated myelitis of the cervical and dorsal cord of probable demyelinating origin, MT-MRI abnormalities are limited to the cord and tend to spare the brain. ${ }^{103,104}$

\section{CNS vasculitis}

Studies of CNS vasculitis have shown that MTR values of T2-visible lesions of patients with systemic lupus erythematosus ${ }^{105,106}$ or other systemic autoimmune diseases (including Wegener's granulomatosis, Behçet's disease, and antiphospholipid antibody syndrome) ${ }^{106}$ are significantly lower than those of the NAWM, even if MTR decreases are less pronounced than those seen in patients with MS. In patients with neuro-systemic lupus erythematosus, MTR changes have also been found in the NAWM ${ }^{105-108}$ and have been correlated with the severity of cognitive and neurological impairment, ${ }^{109}$ as well as with the activity of the disease. ${ }^{107}$ Marked GMMTR decrease has also been shown in patients with neuro-systemic lupus erythematosus. ${ }^{110,111}$

\section{Hypoxic-ischemic cerebral vasculopathies}

An important and common differential diagnosis of WM lesions in patients suspected of having MS is the possibility that these lesions can be caused by hypoxicischemic cerebral small-vessel disorders, which are usually asymptomatic, but can also present with migraine, transient ischemic attacks, stroke, or subcortical arteriosclerotic encephalopathy.

\section{Stroke}

Although MT-MRI is less sensitive than diffusion tensor MRI for detecting ischemic changes during the acute and subacute phases of a stroke, ${ }^{112}$ reduced MTR values have been demonstrated in chronic ischemic lesions, thus suggesting a role for MT-MRI in providing useful pieces of information to estimate the age of cerebral infarcts. ${ }^{112}$ In patients with stroke, MTR of the internal capsule was found to be strongly correlated with the severity of motor deficits. ${ }^{113}$ In patients with occlusive cerebrovascular disease, a strong correlation has been found between MTR measured from the WM of the affected hemisphere and regional cerebral metabolic rate of oxygen. ${ }^{114}$

\section{Migraine}

In patients with migraine and WM lesions, MTR values of T2-visible lesions are lower than those of WM from normal controls, but significantly higher than those of MS. ${ }^{115}$ No MTR abnormalities have been detected in the NABT ${ }^{115}$ and the cervical cord. ${ }^{116}$

\section{Cerebral autosomal dominant arteriopathy with subcortical infarcts and leukoencephalopathy}

In WM lesions of patients with cerebral autosomal dominant arteriopathy with subcortical infarcts and leukoencephalopathy (CADASIL), ${ }^{117}$ a reduction of MTR values with a magnitude comparable to that seen in MS lesions has been found. MT-MRI abnormalities in CADASIL patients are not limited to macroscopic brain lesions, but involve extensively the brain NAWM ${ }^{117}$ and the cervical cord. ${ }^{118}$ In these patients, cord MTR was significantly correlated with the extent of brain lesions (suggesting wallerian degeneration as the most likely substrate of cord MTR changes $)^{118}$ and brain NAWM MTR was found to be correlated with the severity of physical disability and cognitive impairment. ${ }^{117}$

\section{Leber's hereditary optic neuropathy}

In patients with Leber's hereditary optic neuropathy, MTR changes seem to be confined to the optic nerves and brain T2-visible lesions, when present. ${ }^{119}$

\section{Traumatic brain injury (TBI)}

In patients with TBI and no brain MRI-visible lesions, MT-MRI can reveal the presence of microstructural tissue damage in regions known to be susceptible to TBIrelated axonal damage, such as the pons and the splenium of the corpus callosum. ${ }^{120,121}$ The correlation between MTR changes and subsequent clinical recovery remains controversial. ${ }^{120-122}$ The detection of abnormal MTR values in the NAWM of TBI patients has been shown to predict a poor clinical outcome, but normal MTR findings are not necessarily associated with a good functional recovery. ${ }^{120-122}$ Contrary to what is seen in MS, ${ }^{24,25}$ there is an abrupt transition of MTR values between macroscopic lesions of patients with TBI and the surrounding NAWM. ${ }^{6}$ 


\section{Other conditions}

Cerebrotendinous xanthomatosis. MTR changes in the NAWM and GM have been found in patients with cerebrotendinous xanthomatosis and have been shown to be correlated with disability. ${ }^{123}$

Fabry's disease. Subtle MTR changes have been described in lesions and NAWM of patients with Fabry's disease. $^{124}$

\section{MT-MRI IN INFECTIOUS DISEASES}

\section{Neuroborreliosis}

In patients with neuroborreliosis, no MT-MRI abnormalities have been detected in NAWM and GM, nor in the cervical cord. ${ }^{125}$ Similarly, no NAWM MTR changes have been detected in patients with post-treatment Lyme disease syndrome, ${ }^{126}$ suggesting that this technique might be useful in the diagnostic work-up of patients with neuroborreliosis and T2-visible brain lesions undistinguishable from those of MS.

\section{Human immunodeficiency virus-encephalitis and progressive multifocal leukoencephalopathy}

In patients affected by human immunodeficiency virus (HIV)-encephalitis, MTR values of T2-visible lesions are reduced, but to a lesser extent than is observed in MS lesions. ${ }^{127}$ MTR changes in the NAWM have been found in patients with HIV-encephalitis, ${ }^{127,128}$ as well as in HIV-infected asymptomatic patients, ${ }^{128}$ and have been correlated with the severity of cognitive impairment. ${ }^{129}$ In patients with acquired immunodeficiency syndrome, MT-MRI improves the differentiation between progressive multifocal leukoencephalopathy and HIV-associated WM lesions, ${ }^{127,130}$ because MTR values of progressive multifocal leukoencephalopathy lesions are significantly lower than those measured in HIV-associated lesions.

\section{Tuberculosis and other infectious conditions}

MT-MRI may be useful to differentiate tuberculosis from similar-appearing infective lesions on MR images, given that the MTR from the thickened meninges of tuberculous meningitis is significantly lower than that measured from the meninges in cryptococcal and pyogenic diseases and significantly higher than that from the meninges in viral meningoencephalitis. ${ }^{131}$ In addition, MTR from T2-visible and occult tuberculomas has been reported to be significantly lower than that of WM, but the MTR of T2-hypointense cysticercus granuloma is significantly higher than that of T2-hypointense tuberculoma. ${ }^{131}$ Similarly, MTR from tuberculous abscesses is lower than that of pyogenic abscesses. ${ }^{132}$ MTR reduction in areas surrounding solitary cysticercal brain cysts was found to correlate with seizure recurrence after stopping antiepileptic treatment. ${ }^{133}$

\section{MT-MRI AND AGING}

Preliminary studies using ROI-based analysis have achieved conflicting results with regard to age-related variations of MTR values in different brain regions. ${ }^{134,135}$ Mehta et al. ${ }^{134}$ did not find significant decreases of MTR with increasing age, whereas Silver et al. ${ }^{135}$ reported significant age-related MTR changes in the corpus callosum and frontal WM. Studies with histogram-based analysis reported a significant, age-related decrease of average MTR and histogram peak height both in the WM and GM. ${ }^{136-139}$

In elderly subjects with WM hyperintensities (WMHs), the MTR of WMHs is significantly lower than that of the NAWM $^{140,141}$ and correlates with the extent of such abnormalities, suggesting similar causative mechanisms. ${ }^{140}$ In addition, significant MTR abnormalities have been detected in the GM of these individuals, compared with healthy elderly subjects without WMHs, ${ }^{142}$ suggesting that these GM abnormalities might be the basis of the mild cognitive deficits that have been reported in some of these individuals. The notion that MTR-related abnormalities might contribute to explanation of age-related cognitive deficits is supported by the finding of moderately reduced MTR values in WMHs of patients with vascular dementia. ${ }^{143}$

\section{MT-MRI IN OTHER CNS DISORDERS}

\section{Alzheimer's disease (AD) and other dementias}

Compared with sex- and age-matched controls, patients with AD have markedly reduced MTR histogram peak height of the cortical GM and temporal lobe GM. ${ }^{144}$ In these patients, a composite MR score based on brain volume and cortical GM MTR histogram peak height was correlated with cognitive impairment $(r=0.65) .{ }^{144}$ This observation has been confirmed by two other studies, which also showed, in patients with mild cognitive impairment (MCI), decreased MTR values of the cortical GM and temporal lobe GM, in the absence of significant volumetric changes. ${ }^{145,146}$ Reductions in MTR histogram peak height for whole brain, temporal lobe, and frontal lobe have also been shown both in patients with $\mathrm{AD}$ and in those with MCI. ${ }^{147}$ Note that, although AD patients had marked volumetric reductions of all the above-mentioned structures, temporal lobe atrophy was detected only in patients with MCI. ${ }^{147}$

MT-MRI measures derived from the whole of the brain tissue, as well as those from temporal and frontal lobes taken in isolation, were strongly correlated with global cognitive deterioration and impairment of several functions in both $\mathrm{AD}$ and MCI patients. ${ }^{147} \mathrm{~A}$ recent MT-MRI study confirmed that the extent of overall NAWM and GM damage is similar in patients with $\mathrm{AD}$ and MCI, ${ }^{148}$ again suggesting that occult structural brain 
changes may be present before the onset of cognitive deficits. Patients with early AD have also been found to have reduced MTR values of the hippocampus. ${ }^{149}$ The latter abnormalities may facilitate differentiating AD patients from patients with dementia with Lewy bodies, in which hippocampal MTR abnormalities are less pronounced. ${ }^{150}$

\section{Huntington's disease}

In a study that explored MTR of caudate nuclei, putamen, periventricular WM, and the whole brain in carriers of Huntington mutation, mild decreases of MTR were observed in the striatum and whole brain. ${ }^{151}$

\section{Parkinson's disease (PD) and allied conditions}

Only a few studies have investigated MTR of the brain in patients with PD; all of them used ROI analysis, with conflicting results. In one study, no difference in MTR of the subcortical GM and WM has been found between patients with idiopathic PD and matched controls, whereas patients with PD and dementia had significantly lower MTR in the subcortical WM, including frontal WM and the genu of the corpus callosum, and those with progressive supranuclear palsy had significantly lower MTR in the subcortical GM, including the putamen, globus pallidus and thalamus. ${ }^{152}$ In another study, lower MTR values in supratentorial WM and brainstem were found in PD patients without dementia, compared with controls. ${ }^{153}$

Eckert et al. ${ }^{154}$ demonstrated changes in the MTR values in the globus pallidus, putamen, caudate nucleus, substantia nigra, and WM in idiopathic PD, in multiple system atrophy, and in progressive supranuclear palsy, matching the pathological features of the underlying disorder. More recently, significant reduction of MTR was found in the substantia nigra, red nucleus, and pons in PD patients in the first year of diagnosis, indicating that MTR analysis may be a useful technique in the assessment of damage in patients with early PD. ${ }^{155}$

Reduced MTR values have also been found in the pons, middle cerebellar peduncle, putamen and WM of the precentral gyrus in patients with multiple system atrophy. ${ }^{156}$ In this latter group of patients, ${ }^{155}$ MTR values of the corticospinal tract were significantly lower in those with corresponding pyramidal signs compared with those without; similarly, MTR values of the basal ganglia were significantly lower in patients with corresponding parkinsonism than in those without it.

\section{Amyotrophic lateral sclerosis}

Reduced MTR values have been reported in the corticospinal tracts of patients with amyotrophic lateral sclerosis ${ }^{157,158}$ and have been correlated with clinical measures of motor neuron function. ${ }^{158}$

\section{Epilepsy}

Reduced MTR histogram peak height of the whole brain has been reported in patients with nocturnal frontal lobe epilepsy ${ }^{159}$ and focal epilepsy, ${ }^{160}$ but not in those with idiopathic generalized epilepsy. ${ }^{160}$ Reduced MTR values of the amygdala and hippocampus were reported in patients with temporal lobe epilepsy, ${ }^{161,162}$ but the MTR changes were concordant with the electroclinical lateralization in only one of these patients. ${ }^{162}$ More recently, a voxel-based morphometry analysis of the distribution of MTR abnormalities in patients with temporal lobe epilepsy and interictal psychosis revealed significant reduction of MTR values in several regions of the temporal lobe in these patients, in the absence of corresponding macroscopic abnormalities in the same regions. ${ }^{163}$

\section{Hydrocephalus}

In patients with normal pressure hydrocephalus ${ }^{164}$ and chronic obstructive hydrocephalus, ${ }^{165}$ MTR abnormalities have been detected in the periventricular NAWM and in the NAWM of the corpus callosum, but no MTR abnormalities have been revealed in the thalami.

\section{Tumors}

MT-MRI has been used to investigate the nature of brain tumors in vivo. ${ }^{166}$ Meningiomas were found to have, on average, higher MTR values than other tumors, and soft tumors were found to have lower MTR values than hard tumors. ${ }^{166}$ The application of an MT pulse to postcontrast $\mathrm{T} 1$-weighted images enabled a higher number of lesions to be detected in patients with brain metastases than did plain T1-weighted images, ${ }^{167,168}$ with a sensitivity similar to that achieved with administration of a triple dose of Gd. ${ }^{168}$

T1-weighted sequences with MT pulse can also contribute to the assessment of patients with tuberous sclerosis. ${ }^{169,170}$ MT-MRI has been proven to be useful for the study of the normal ${ }^{171}$ and pathological ${ }^{172}$ adenohypophysis. In patients with hyperprolactinemia, the MTR of prolactin-secreting tumors is higher and that of the nonsecreting adenomas is lower than the MTR values of the normal pituitary gland of age- and sex-matched controls. ${ }^{172}$ In some patients surgically treated for growth hormone adenomas, increased MTR values were highly suggestive of persistence of adenoma tissue, in agreement with biochemical findings of persisting secretory activity. ${ }^{172}$

\section{Myotonic dystrophy}

Significant MTR reductions of T2-visible lesions and NAWM were seen in patients with myotonic dystrophy and were correlated with the duration of the disease, suggesting that structural changes in the WM of these patients may be progressive. ${ }^{173} \mathrm{~A}$ more recent study showed that neocortical pathology is likely to be impor- 
tant in this CNS affection, as reflected by the presence of reduced volumes and MTR values in the neocortex of patients with myotonic dystrophy. ${ }^{174}$

\section{Psychiatric disorders}

Although not confirmed by all authors, ${ }^{175}$ widespread MTR reductions have been reported in the cortex (predominantly in the frontal and temporal regions), but not in the thalami, ${ }^{176}$ of schizophrenic patients, ${ }^{177}$ from the earliest stages of the disease. ${ }^{178}$ Such MTR changes were unrelated to volume reduction. ${ }^{177}$ Decreased MTR values have also been found in several WM areas of the temporal and frontal lobes in schizophrenic patients ${ }^{177,179,180}$ and have been associated with the severity of negative symptoms. ${ }^{177}$ In the early stages of the disease, such MTR abnormalities tend to remain stable, as suggested by a recent 3.7-year follow-up study. ${ }^{181}$

In patients with bipolar disorders, MTR analysis showed subtle abnormalities in the anterior cingulated and subgyral WM, in the absence of significant volumetric changes in these regions. ${ }^{182}$ More recently, MTR abnormalities in several frontotemporal regions have been correlated with decline in intellectual quotient in these patients. ${ }^{183}$

\section{CONCLUSIONS}

Conventional MRI has markedly increased our ability to detect the macroscopic abnormalities of the brain and spinal cord associated with CNS disorders. New quantitative MR approaches with increased sensitivity to subtle NAWM and GM changes and increased specificity for the heterogeneous pathological substrates of CNS lesions may yield information complementary to that from conventional MRI. Especially in patients with MS and other WM disorders, MT-MRI has the potential to quantify the structural changes occurring within and outside T2-visible lesions.

The application of this technique in patients with a variety of neurological conditions has improved dramatically our understanding of the factors associated with the appearance of clinical symptoms and with the accumulation of irreversible disability. MT-MRI also has the potential to contribute to the diagnostic evaluation of a number of neurological conditions and, as has been shown for MS, the MT-MRI technique can improve our ability to monitor treatment efficacy in experimental trials.

\section{REFERENCES}

1. Wolff SD, Balaban RS. Magnetization transfer imaging: practical aspects and clinical applications. Radiology 1994;192:593-599.

2. Balaban RS, Ceckler TL. Magnetization transfer contrast in magnetic resonance imaging. Magn Reson Q 1992;8:116-137.

3. Wolff SD, Balaban RS. Magnetization transfer contrast (MTC) and tissue water proton relaxation in vivo. Magn Reson Med 1989;10:135-144.
4. Henkelman RM, Huang XM, Xiang QS, Stanisz GJ, Swanson SD, Bronskill MJ. Quantitative interpretation of magnetization transfer. Magn Reson Med 1993;29:759-766.

5. McGowan JC, McCormack TM, Grossman RI, et al. Diffuse axonal pathology detected with magnetization transfer imaging following brain injury in the pig. Magn Reson Med 1999;41:727733.

6. Bagley LJ, Grossman RI, Galetta SL, Sinson GP, Kotapka M, McGowan JC. Characterization of white matter lesions in multiple sclerosis and traumatic brain injury as revealed by magnetization transfer contour plots. AJNR Am J Neuroradiol 1999;20: 977-981.

7. van Buchem MA, McGowan JC, Kolson DL, Polansky M, Grossman RI. Quantitative volumetric magnetization transfer analysis in multiple sclerosis: estimation of macroscopic and microscopic disease burden. Magn Reson Med 1996;36:632-636.

8. Sormani MP, Iannucci G, Rocca MA, et al. Reproducibility of magnetization transfer ratio histogram-derived measures of the brain in healthy volunteers. AJNR Am J Neuroradiol 2000;21: 133-136.

9. Inglese M, Horsfield MA, Filippi M. Scan-rescan variation of measures derived from brain magnetization transfer histograms obtained in healthy volunteers by use of a semi-interleaved magnetization transfer sequence. AJNR Am J Neuroradiol 2001;22: 681-684.

10. Audoin B, Ranjeva JP, van Au Dong M, et al. Voxel-based analysis of MTR images: a method to locate gray matter abnormalities in patients at the earliest stage of multiple sclerosis. J Magn Reson Imaging 2004;20:765-771.

11. Ranjeva JP, Audoin B, van Au Dong M, et al. Local tissue damage assessed with statistical mapping analysis of brain magnetization transfer ratio: relationship with functional status of patients in the earliest stage of multiple sclerosis. AJNR Am J Neuroradiol 2005;26:119-127.

12. Silver NC, Lai M, Symms MR, Barker GJ, McDonald WI, Miller DH. Serial magnetization transfer imaging to characterize the early evolution of new MS lesions. Neurology 1998;51:758-764.

13. Campi A, Filippi M, Comi G, Scotti G, Gerevini S, Dousset V. Magnetisation transfer ratios of contrast-enhancing and nonenhancing lesions in multiple sclerosis. Neuroradiology 1996;38: $115-119$.

14. Hiehle JF, Grossman RI, Ramer NK, Gonzalez-Scarano F, Cohen JA. Magnetization transfer effects in MR-detected multiple sclerosis lesions: comparison with gadolinium-enhanced spin-echo images and non-enhanced T1-weighted images. AJNR Am J Neuroradiol 1995;16:69-77.

15. Petrella JR, Grossman RI, McGowan JC, Campbell G, Cohen JA. Multiple sclerosis lesions: relationship between MR enhancement pattern and magnetization transfer effect. AJNR Am J Neuroradiol 1996;17:1041-1049.

16. Filippi M, Rocca MA, Comi G. Magnetization transfer ratios of multiple sclerosis lesions with variable durations of enhancement. J Neurol Sci 1998;159:162-165.

17. Filippi M, Rocca MA, Rizzo G. Magnetization transfer ratios in MS lesions enhancing after different doses of gadolinium. Neurology 1998;50:1289-1293.

18. Lassmann H, Suchanek G, Ozawa K. Histopathology and the blood-cerebrospinal fluid barrier in multiple sclerosis. Ann Neurol 1994;36:42-46.

19. Metha RC, Pike GB, Enzmann DR. Measure of magnetization transfer in multiple sclerosis demyelinating plaques, white matter ischemic lesions, and edema. AJNR Am J Neuroradiol 1996;17: 1051-1055.

20. Schmierer K, Scaravilli F, Altmann DR, Barker GJ, Miller DH. Magnetization transfer ratio and myelin in postmortem multiple sclerosis brain. Ann Neurol 2004;56:407-415.

21. Bastianello S, Gasperini C, Paolillo A, et al. Sensitivity of enhanced MR in multiple sclerosis: effects of contrast dose and magnetization transfer contrast. AJNR Am J Neuroradiol 1998; 19:1863-1867.

22. Gass A, Barker GJ, Kidd D, et al. Correlation of magnetization transfer ratio with disability in multiple sclerosis. Ann Neurol 1994;36:62-67. 
23. van Walderveen MA, Kamphorst W, Scheltens P, et al. Histopathologic correlate of hypointense lesions on T1-weighted spin-echo MRI in multiple sclerosis. Neurology 1998;50:1282-1288.

24. Filippi M, Iannucci G, Tortorella C, et al. Comparison of MS clinical phenotypes using conventional and magnetization transfer MRI. Neurology 1999;52:588-594.

25. Filippi M, Campi A, Dousset V, et al. A magnetization transfer imaging study of normal-appearing white matter in multiple sclerosis. Neurology 1995;45:478-482.

26. Loevner LA, Grossman RI, Cohen JA, Lexa FJ, Kessler D, Kolson DL. Microscopic disease in normal-appearing white matter on conventional MR imaging in patients with multiple sclerosis: assessment with magnetization-transfer measurements. Radiology 1995;196:511-515.

27. Guo AC, Jewells VL, Provenzale JM. Analysis of normal-appearing white matter in multiple sclerosis: comparison of diffusion tensor MR imaging and magnetization transfer imaging. AJNR Am J Neuroradiol 2001;22:1893-1900.

28. Ge Y, Grossman RI, Babb JS, He J, Mannon LJ. Dirty-appearing white matter in multiple sclerosis: volumetric MR imaging and magnetization transfer ratio histogram analysis. AJNR Am J Neuroradiol 2003;24:1935-1940.

29. Iannucci G, Tortorella C, Rovaris M, Sormani MP, Comi G, Filippi M. Prognostic value of MR and magnetization transfer imaging findings at presentation in patients with clinically isolated syndromes suggestive of multiple sclerosis at presentation. AJNR Am J Neuroradiol 2000;21:1034-1038.

30. De Stefano N, Battaglini M, Stromillo ML, et al. Brain damage as detected by magnetization transfer imaging is less pronounced in benign than in early relapsing multiple sclerosis. Brain 2006;129: 2008-2016.

31. Rovaris M, Bozzali M, Santuccio G, et al. In vivo assessment of the brain and cervical cord pathology of patients with primary progressive multiple sclerosis. Brain 2001;124:2540-2549.

32. Rocca MA, Mastronardo G, Rodegher M, Comi G, Filippi M. Long-term changes of magnetization transfer-derived measures from patients with relapsing-remitting and secondary-progressive multiple sclerosis. AJNR Am J Neuroradiol 1999;20:821-827.

33. Filippi M, Tortorella C, Rovaris M, et al. Changes in the normal appearing brain tissue and cognitive impairment in multiple sclerosis. J Neurol Neurosurg Psychiatry 2000;68:157-161.

34. Agosta F, Rovaris M, Pagani E, Sormani MP, Comi G, Filippi M. Magnetization transfer MRI metrics predict the accumulation of disability 8 years later in patients with multiple sclerosis. Brain 2006;129:2620-2627.

35. Rocca MA, Falini A, Colombo B, Scotti G, Comi G, Filippi M. Adaptive functional changes in the cerebral cortex of patients with nondisabling multiple sclerosis correlate with the extent of brain structural damage. Ann Neurol 2002;51:330-339.

36. Filippi M, Rocca MA. Cortical reorganisation in patients with MS: using functional MRI techniques to study patients with MS [Editorial]. J Neurol Neurosurg Psychiatry 2004;75:1087-1089.

37. Arstila AU, Riekkinen P, Rinne UK, Laitinen L. Studies on the pathogenesis of multiple sclerosis: participation of lysosomes on demyelination in the central nervous system white matter outside plaques. Eur Neurol 1973;9:1-20.

38. Allen IV, McKeown SR. A histological, histochemical and biochemical study of the macroscopically normal white matter in multiple sclerosis. J Neurol Sci 1979;41:81-91.

39. Bjartmar C, Kinkel RP, Kidd G, Rudick RA, Trapp BD. Axonal loss in normal-appearing white matter in a patient with acute MS. Neurology 2001;57:1248-1252.

40. Evangelou N, Esiri MM, Smith S, Palace J, Matthews PM. Quantitative pathological evidence for axonal loss in normal appearing white matter in multiple sclerosis. Ann Neurol 2000;47:391-395.

41. Dehmeshki J, Silver NC, Leary SM, Tofts PS, Thompson AJ, Miller DH. Magnetisation transfer ratio histogram analysis of primary progressive and other multiple sclerosis subgroups. J Neurol Sci 2001;185:11-17.

42. Kalkers NF, Hintzen RQ, van Waesberghe JH, et al. Magnetization transfer histogram parameters reflect all dimensions of MS pathology, including atrophy. J Neurol Sci 2001;184:155-162 [Erratum in: J Neurol Sci 2001;187:111].
43. Ge Y, Grossman RI, Udupa JK, Babb JS, Mannon LJ, McGowan JC. Magnetization transfer ratio histogram analysis of normalappearing gray matter and normal-appearing white matter in multiple sclerosis. J Comput Assist Tomogr 2002;26:62-68.

44. Traboulsee A, Dehmeshki J, Brex PA, et al. Normal-appearing brain tissue MTR histograms in clinically isolated syndromes suggestive of MS. Neurology 2002;59:126-128.

45. Davies GR, Altmann DR, Hadjiprocopis A, et al. Increasing normal-appearing grey and white matter magnetisation transfer ratio abnormality in early relapsing-remitting multiple sclerosis. J Neurol 2005;252:1037-1044.

46. Fernando KT, Tozer DJ, Miszkiel KA, et al. Magnetization transfer histograms in clinically isolated syndromes suggestive of multiple sclerosis. Brain 2005;128:2911-2925.

47. Ramio-Torrenta L, Sastre-Garriga J, Ingle GT, et al. Abnormalities in normal appearing tissues in early primary progressive multiple sclerosis and their relation to disability: a tissue specific magnetisation transfer study. J Neurol Neurosurg Psychiatry 2006;77:40-45.

48. Filippi M, Rocca MA, Martino G, Horsfield MA, Comi G. Magnetization transfer changes in the normal appearing white matter precede the appearance of enhancing lesions in patients with multiple sclerosis. Ann Neurol 1998;43:809-814.

49. Goodkin DE, Rooney WD, Sloan R, et al. A serial study of new MS lesions and the white matter from which they arise. Neurology 1998;51:1689-1697.

50. Pike GB, De Stefano N, Narayanan S, et al. Multiple sclerosis: magnetization transfer MR imaging of white matter before lesion appearance on T2-weighted images. Radiology 2000;215:824830.

51. Fazekas F, Ropele S, Enziger C, Seifert T, Strasser-Fuchs S. Quantitative magnetization transfer imaging of pre-lesional white-matter changes in multiple sclerosis. Mult Scler 2002;8: 479-484.

52. Mezzapesa DM, Rocca MA, Falini A, et al. A preliminary diffusion tensor and magnetization transfer magnetic resonance imaging study of early-onset multiple sclerosis. Arch Neurol 2004;61: 366-368.

53. Iannucci G, Minicucci L, Rodegher M, Sormani MP, Comi G, Filippi M. Correlations between clinical and MRI involvement in multiple sclerosis: assessment using $\mathrm{T}_{1}, \mathrm{~T}_{2}$ and MT histograms. J Neurol Sci 1999;171:121-129.

54. Dehmeshki J, Ruto AC, Arridge S, Silver NC, Miller DH, Tofts PS. Analysis of MTR histograms in multiple sclerosis using principal components and multiple discriminant analysis. Magn Reson Med 2001;46:600-609.

55. Traboulsee A, Dehmeshki J, Peters KR, et al. Disability in multiple sclerosis is related to normal appearing brain tissue MTR histogram abnormalities. Mult Scler 2003;9:566-573.

56. Rovaris M, Filippi M, Falautano M, et al. Relation between MR abnormalities and patterns of cognitive impairment in multiple sclerosis. Neurology 1998;50:1601-1608.

57. van Buchem MA, Grossman RI, Armstrong C, et al. Correlation of volumetric magnetization transfer imaging with clinical data in MS. Neurology 1998;50:1609-1617.

58. Cox D, Pelletier D, Genain C, et al. The unique impact of changes in normal appearing brain tissue on cognitive dysfunction in secondary progressive multiple sclerosis patients. Mult Scler 2004; 10:626-629.

59. Deloire MS, Salort E, Bonnet M, et al. Cognitive impairment as marker of diffuse brain abnormalities in early relapsing remitting multiple sclerosis. J Neurol Neurosurg Psychiatry 2005;76:519526.

60. Codella M, Rocca MA, Colombo B, Rossi P, Comi G, Filippi M. A preliminary study of magnetization transfer and diffusion tensor MRI of multiple sclerosis patients with fatigue. J Neurol 2002;249:535-537.

61. Filippi M, Inglese M, Rovaris M, et al. Magnetization transfer imaging to monitor the evolution of MS: a 1-year follow-up study. Neurology 2000;55:940-946.

62. Kaiser JS, Grossman RI, Polansky M, Udupa JK, Miki Y, Galetta SL. Magnetization transfer histogram analysis of monosymptom- 
atic episodes of neurologic dysfunction: preliminary findings. AJNR Am J Neuroradiol 2000;21:1043-1047.

63. Brex PA, Leary SM, Plant GT, Thompson AJ, Miller DH. Magnetization transfer imaging in patients with clinically isolated syndromes suggestive of multiple sclerosis. AJNR Am J Neuroradiol 2001;22:947-951.

64. Santos AC, Narayanan S, De Stefano N, et al. Magnetization transfer can predict clinical evolution in patients with multiple sclerosis. J Neurol 2002;249:662-668.

65. Rovaris M, Agosta F, Sormani MP, et al. Conventional and magnetization transfer MRI predictors of clinical multiple sclerosis evolution: a medium-term follow-up study. Brain 2003;126: 2323-2332.

66. Tortorella C, Viti B, Bozzali M, et al. A magnetization transfer histogram study of normal-appearing brain tissue in multiple sclerosis. Neurology 2000;54:186-193.

67. Filippi M, Rocca MA, Falini A, et al. Correlations between structural CNS damage and functional MRI changes in primary progressive MS. Neuroimage 2002;15:537-546.

68. Brownell B, Hughes JT. The distribution of plaques in the cerebrum in multiple sclerosis. J Neurol Neurosurg Psychiatry 1962; 25:315-320.

69. Lumsden CE. The neuropathology of multiple sclerosis. In: Vinken PJ, Bruyn GW, editors. Multiple sclerosis and other demyelinating diseases. Handbook of Clinical Neurology 9. Amsterdam: North-Holland; 1970;217-309.

70. Kidd D, Barkhof F, McConnell R, Algra PR, Allen IV, Revesz T. Cortical lesions in multiple sclerosis. Brain 1999;122:17-26.

71. Peterson JW, Bo L, Mork S, Chang A, Trapp BD. Transected neurites, apoptotic neurons, and reduced inflammation in cortical multiple sclerosis lesions. Ann Neurol 2001;50:389-400.

72. Cercignani M, Bozzali M, Iannucci G, Comi G, Filippi M. Magnetisation transfer ratio and mean diffusivity of normal appearing white and grey matter from patients with multiple sclerosis. J Neurol Neurosurg Psychiatry 2001;70:311-317.

73. Ge Y, Grossman RI, Udupa JK, Babb JS, Kolson DL, McGowan JC. Magnetization transfer ratio histogram analysis of gray matter in relapsing-remitting multiple sclerosis. AJNR Am J Neuroradiol 2001;22:470-475.

74. Dehmeshki J, Chard DT, Leary SM, et al. The normal appearing grey matter in primary progressive multiple sclerosis: a magnetisation transfer imaging study. J Neurol 2003;250:67-74.

75. Audoin B, Fernando KT, Swanton JK, Thompson AJ, Plant GT, Miller DH. Selective magnetization transfer ratio decrease in the visual cortex following optic neuritis. Brain 2006;129:10311039.

76. Davies GR, Altmann DR, Rashid W, et al. Emergence of thalamic magnetization transfer ratio abnormality in early relapsing-remitting multiple sclerosis. Mult Scler 2005;11:276-281.

77. Sharma J, Zivadinov R, Jaisani Z, et al. A magnetization transfer MRI study of deep gray matter involvement in multiple sclerosis. J Neuroimaging 2006;16:302-310.

78. Oreja-Guevara C, Charil A, Caputo D, Cavarretta R, Sormani MP, Filippi M. Magnetization transfer magnetic resonance imaging and clinical changes in patients with relapsing-remitting multiple sclerosis. Arch Neurol 2006;63:736-740.

79. Codella M, Rocca MA, Colombo B, Martinelli-Boneschi F, Comi G, Filippi M. Cerebral grey matter pathology and fatigue in patients with multiple sclerosis: a preliminary study. J Neurol Sci 2002;194:71-74.

80. Filippi M, Dousset V, McFarland HF, Miller DH, Grossman RI. Role of magnetic resonance imaging in the diagnosis and monitoring of multiple sclerosis: consensus report of the White Matter Study Group. J Magn Reson Imaging 2002;15:499-504.

81. Horsfield MA, Barker GJ, Barkhof F, Miller DH, Thompson AJ, Filippi M. Guidelines for using quantitative magnetization transfer magnetic resonance imaging for monitoring treatment of multiple sclerosis. J Magn Reson Imaging 2003;17:389-397.

82. Richert ND, Ostuni JL, Bash CN, Duyn JH, McFarland HF, Frank JA. Serial whole-brain magnetization transfer imaging in patients with relapsing-remitting multiple sclerosis at baseline and during treatment with interferon beta-1b. AJNR Am J Neuroradiol 1998; 19:1705-1713.
83. Richert ND, Ostuni JL, Bash CN, Leist TP, McFarland HF, Frank $\mathrm{JA}$. Interferon beta- $1 \mathrm{~b}$ and intravenous methylprednisolone promote lesion recovery in multiple sclerosis. Mult Scler 2001;7:49-58.

84. Kita M, Goodkin DE, Bacchetti P, Waubant E, Nelson SJ, Majumdar S. Magnetization transfer ratio in new MS lesions before and during therapy with IFN $\beta-1$ a. Neurology 2000;54:17411745.

85. Fox RJ, Fisher E, Tkach J, Lee JC, Cohen JA, Rudick RA. Brain atrophy and magnetization transfer ratio following methylprednisolone in multiple sclerosis: short-term changes and long-term implications. Mult Scler 2005;11:140-145.

86. Inglese M, van Waesberghe JHTM, Rovaris M, et al. The effect of interferon $\beta-1 \mathrm{~b}$ on quantities derived from MT MRI in secondary progressive MS. Neurology 2003;60:853-860.

87. Filippi M, Rocca MA, Pagani E, et al. European Study on Intravenous Immunoglobulin in Multiple Sclerosis: results of magnetization transfer magnetic resonance imaging analysis. Arch Neurol 2004;61:1409-1412.

88. Miller DH, Molyneux PD, Barker GJ, MacManus DG, Moseley IF, Wagner K. Effect of interferon-beta $1 \mathrm{~b}$ on magnetic resonance imaging outcomes in secondary progressive multiple sclerosis: results of a European multicenter, randomized, double-blind, placebo-controlled trial. Ann Neurol 1999;46:850-859.

89. Lin X, Turner B, Costantinescu. Cerebral volume change in secondary progressive multiple sclerosis: effect of intravenous immunoglobulins (IVIG). J Neurol 2002;249(Suppl 1):169. Abstract.

90. Silver NC, Barker GJ, Losseff NA, et al. Magnetisation transfer ratio measurement in the cervical spinal cord: a preliminary study in multiple sclerosis. Neuroradiology 1997;39:441-445.

91. Bozzali M, Rocca MA, Iannucci G, Pereira C, Comi G, Filippi M. Magnetization transfer histogram analysis of the cervical cord in patients with multiple sclerosis. AJNR Am J Neuroradiol 1999; 20:1803-1808.

92. Filippi M, Bozzali M, Horsfield MA, et al. A conventional and magnetization transfer MRI study of the cervical cord in patients with MS. Neurology 2000;54:207-213.

93. Rovaris M, Bozzali M, Santuccio G, et al. Relative contributions of brain and cervical cord pathology to multiple sclerosis disability: a study with magnetisation transfer ratio histogram analysis. J Neurol Neurosurg Psychiatry 2000;69:723-727.

94. Thorpe JW, Barker GJ, Jones SJ, et al. Magnetisation transfer ratios and transverse magnetisation decay curves in optic neuritis: correlation with clinical findings and electrophysiology. J Neurol Neurosurg Psychiatry 1995;58:487-492.

95. Boorstein JM, Moonis G, Boorstein SM, Patel YP, Culler AS Optic neuritis: imaging with magnetization transfer. AJR Am J Roentgenol 1997;169:1709-1712.

96. Inglese M, Ghezzi A, Bianchi S, et al. Irreversible disability and tissue loss in multiple sclerosis: a conventional and magnetization transfer magnetic resonance imaging study of the optic nerves. Arch Neurol 2002;59:250-255.

97. Hickman SJ, Toosy AT, Jones SJ, et al. Serial magnetization transfer imaging in acute optic neuritis. Brain 2004;127:692-700.

98. Melzi L, Rocca MA, Bianchi Marzoli S, et al. A longitudinal conventional and magnetization transfer magnetic resonance imaging study of optic neuritis. Mult Scler 2007;13:265-268.

99. Rovaris M, Gallo A, Riva R, et al. An MT MRI study of the cervical cord in clinically isolated syndromes suggestive of MS Neurology 2004;63:584-585.

100. Filippi M, Rocca MA, Moiola L, et al. MRI and magnetization transfer imaging changes in the brain and cervical cord of patients with Devic's neuromyelitis optica. Neurology 1999; 53:1705-1710.

101. Rocca MA, Agosta F, Mezzapesa DM, et al. Magnetization transfer and diffusion tensor MRI show gray matter damage in neuromyelitis optica. Neurology 2004;62:476-478.

102. Inglese M, Salvi F, Iannucci G, Mancardi GL, Mascalchi M, Filippi M. Magnetization transfer and diffusion tensor MR imaging of acute disseminated encephalomyelitis. AJNR Am J Neuroradiol 2002;23:267-272. 
103. Rocca MA, Mezzapesa DM, Ghezzi A, et al. Cord damage elicits brain functional reorganization after a single episode of myelitis. Neurology 2003;61:1078-1085.

104. Rocca MA, Agosta F, Martinelli V, Falini A, Comi G, Filippi M. The level of spinal cord involvement influences the pattern of movement-associated cortical recruitment in patients with isolated myelitis. Neuroimage 2006;30:879-384.

105. Campi A, Filippi M, Gerevini S, et al. Multiple white matter lesions of the brain: magnetization transfer ratios in systemic lupus erythematosus and multiple sclerosis. Int $\mathbf{J}$ Neuroradiol 1996;2:134-140.

106. Rovaris M, Viti B, Ciboddo G, et al. Brain involvement in systemic immune-mediated diseases: a magnetic resonance and magnetization transfer imaging study. J Neurol Neurosurg Psychiatry 1999;68:170-177.

107. Bosma GPT, Rood MJ, Huizinga TWJ, De Jong BA, Bollen ELEM, van Buchem MA. Detection of cerebral involvement in patients with active neuropsychiatric systemic lupus erythematosus by the use of volumetric magnetization transfer imaging. Arthritis Rheum 2000;43:2428-2436.

108. Dehmeshki J, van Buchem MA, Bosma GPT, Huizinga TWJ, Tofts PS. Systemic lupus erythematosis: diagnostic application of magnetization transfer ratio histograms in patients with neuropsychiatric symptoms - initial results. Radiology 2002;222:722-728.

109. Bosma GPT, Middelkoop HAM, Rood MJ, Bollen ELEM, Huizinga TWJ, van Buchem MA. Association of global brain damage and clinical functioning in neuropsychiatric systemic lupus erythematisus. Arthritis Rheum 2002;46:2665-2672.

110. Steens SC, Admiraal-Behloul F, Bosma GP, et al. Selective gray matter damage in neuropsychiatric lupus. Arthritis Rheum 2004; 50:2877-2881.

111. Steens SC, Bosma GP, Steup-Beekman GM, le Cessie S, Huizinga TW, van Buchem MA. Association between microscopic brain damage as indicated by magnetization transfer imaging and anticardiolipin antibodies in neuropsychiatric lupus. Arthritis Res Ther 2006;8:R38. Abstract.

112. Hanyu H, Imon Y, Sakurai H, et al. Diffusion-weighted magnetic resonance and magnetization transfer imaging in the assessment of ischemic human stroke. Intern Med 1998;37:360-365.

113. Pendlebury ST, Lee MA, Blamire AM, Styles P, Matthews PM. Correlating magnetic resonance imaging markers of axonal injury and demyelination in motor impairment secondary to stroke and multiple sclerosis. Magn Reson Imaging 2000;18:369-378.

114. Kado H, Kimura H, Tsuchida T, et al. Abnormal magnetization transfer ratios in normal-appearing white matter on conventional MR images of patients with occlusive cerebrovascular disease. AJNR Am J Neuroradiol 2001;22:922-927.

115. Rocca MA, Colombo B, Pratesi A, Comi G, Filippi M. A magnetization transfer imaging study of the brain in patients with migraine. Neurology 2000;54:507-509.

116. Rovaris M, Bozzali M, Rocca MA, Colombo B, Filippi M. An MR study of tissue damage in the cervical cord of patients with migraine. J Neurol Sci 2001;183:43-46.

117. Iannucci G, Dichgans M, Rovaris M, et al. Correlations between clinical findings and magnetization transfer imaging metrics of tissue damage in individuals with cerebral autosomal dominant arteriopathy with subcortical infarcts and leukoencephalopathy. Stroke 2001;32:643-648.

118. Rocca MA, Filippi M, Herzog J, Sormani MP, Dichgans M, Yousry TA. A magnetic resonance imaging study of the cervical cord of patients with CADASIL. Neurology 2001;56:1392-1394.

119. Inglese $M$, Rovaris $M$, Bianchi $S$, et al. Magnetic resonance imaging, magnetisation transfer imaging, and diffusion weighted imaging correlates of optic nerve, brain, and cervical cord damage in Leber's hereditary optic neuropathy. J Neurol Neurosurg Psychiatry 2001;70:444-449.

120. Bagley LJ, McGowan JC, Grossman RI, et al. Magnetization transfer imaging of traumatic brain injury. J Magn Reson Imaging 2000;11:1-8.

121. McGowan JC, Yang JH, Plotkin RC, et al. Magnetization transfer imaging in the detection of injury associated with mild head trauma. AJNR Am J Neuroradiol 2000;21:875-880.

122. Sinson G, Bagley LJ, Cecil KM, et al. Magnetization transfer imaging and proton MR spectroscopy in the evaluation of axonal injury: correlation with clinical outcome after traumatic brain injury. AJNR Am J Neuroradiol 2001;22:143-151.

123. Inglese M, DeStefano N, Pagani E, et al. Quantification of brain damage in cerebrotendinous xanthomatosis with magnetization transfer MR imaging. AJNR Am J Neuroradiol 2003;24:495-500.

124. Marino S, Borsini W, Buchner S, et al. Diffuse structural and metabolic brain changes in Fabry disease. J Neurol 2006;253: 434-440.

125. Agosta F, Rocca MA, Benedetti B, Capra R, Cordioli C, Filippi M. MR imaging assessment of brain and cervical cord damage in patients with neuroborreliosis. AJNR Am J Neuroradiol 2006;27: 892-894.

126. Morgen K, Martin R, Stone RD, et al. FLAIR and magnetization transfer imaging of patients with post-treatment Lyme disease syndrome. Neurology 2001;57:1980-1985.

127. Dousset V, Armand JP, Lacoste D, et al. Magnetization transfer study of HIV encephalitis and progressive multifocal leukoencephalopathy. AJNR Am J Neuroradiol 1997;18:859-901.

128. Ge Y, Kolson DL, Babb JS, Mannon LJ, Grossman RI. Whole brain imaging of HIV-infected patients: quantitative analysis of magnetization transfer ratio histogram and fractional brain volume. AJNR Am J Neuroradiol 2003;24:82-87.

129. Ragin AB, Storey P, Cohen BA, Edelman RR, Epstein LG. Disease burden in HIV-associated cognitive impairment: a study of whole-brain imaging measures. Neurology 2004;63:2293-2297.

130. Ernst T, Chang L, Witt M, et al. Progressive multifocal leukoencephalopathy and human immunodeficiency virus-associated white matter lesions in AIDS: magnetization transfer MR imaging. Radiology 1999;210:539-543.

131. Gupta RK, Kathuria KM, Pradhan S. Magnetization transfer MR imaging in CNS tuberculosis. AJNR Am J Neuroradiol 1999;20: $867-875$.

132. Gupta RK, Vatsal DK, Husain N, et al. Differentiation of tuberculous from pyogenic brain abscesses with in vivo proton MR spectroscopy and magnetization transfer MR imaging. AJNR Am J Neuroradiol 2001;22:1503-1509.

133. Pradhan S, Kathuria MK, Gupta RK. Perilesional gliosis and seizure outcome: a study based on magnetization transfer magnetic resonance imaging in patients with neurocysticercosis. Ann Neurol 2000;48:181-187.

134. Mehta RC, Pike GB, Enzmann DR. Magnetization transfer MR of the normal adult brain. AJNR Am J Neuroradiol 1995;16:20852091.

135. Silver NC, Barker GJ, MacManus DG, Tofts PS, Miller DH Magnetisation transfer ratio of normal brain white matter: a normative database spanning four decades of life. J Neurol Neurosurg Psychiatry 1997;62:223-228.

136. Hofman PAM, Kemerink GJ, Jolles J, Wilmink JT. Quantitative analysis of magnetization transfer images of the brain: effect of closed head injury, age and sex on white matter. Magn Reson Med 1999;42:803-806.

137. Ge Y, Grossman RI, Babb JS, Rabin ML, Mannon LJ, Kolson DL. Age-related total gray matter and white matter changes in normal adult brain. Part II: Quantitative magnetization transfer ratio histogram analysis. AJNR Am J Neuroradiol 2002;23:13341341.

138. Rovaris M, Iannucci G, Cercignani M, et al. Age-related changes of conventional, magnetization transfer and diffusion tensor MRI findings: a study with whole brain tissue histogram analysis. Radiology 2003;227:731-738.

139. Benedetti B, Charil A, Rovaris M, et al. Influence of aging on brain gray and white matter changes assessed by conventional, MT, and DT MRI. Neurology 2006;66:535-539.

140. Fazekas F, Ropele S, Enzinger C, et al. MTI of white matter hyperintensities. Brain 2005;128:2926-2932.

141. Spilt A, Goekoop R, Westendorp RG, Blauw GJ, de Craen AJ, van Buchem MA. Not all age-related white matter hyperintensities are the same: a magnetization transfer imaging study. AJNR Am J Neuroradiol 2006;27:1964-1968.

142. Mezzapesa DM, Rocca MA, Pagani E, Comi G, Filippi M. Evidence of subtle gray-matter pathologic changes in healthy elderly 
individuals with nonspecific white-matter hyperintensities. Arch Neurol 2003;60:1109-1112.

143. Tanabe JL, Ezekiel F, Jagust WJ, et al. Magnetization transfer ratio of white matter hyperintensities in subcortical ischemic vascular dementia. AJNR Am J Neuroradiol 1999;20:839-844.

144. Bozzali M, Franceschi M, Falini A, et al. Quantification of tissue damage in $\mathrm{AD}$ using diffusion tensor and magnetization transfer MRI. Neurology 2001;57:1135-1137.

145. Kabani NJ, Sled JG, Chertkow H. Magnetization transfer ration in mild cognitive impairment and dementia of Alzheimer's type. Neuroimage 2002;15:604-610.

146. Kabani NJ, Sled JG, Shuper A, Chertkow H. Regional magnetization transfer ratio changes in mild cognitive impairment. Magn Reson Med 2002;47:143-148.

147. Van der Flier WM, van den Heuvel DMJ, Weverling-Rijnsburger AWE, et al. Magnetization transfer imaging in normal aging, mild cognitive impairment and Alzheimer's disease. Ann Neurol 2002; 52:62-67.

148. van Es AC, van der Flier WM, Admiraal-Behloul F, et al. Magnetization transfer imaging of gray and white matter in mild cognitive impairment and Alzheimer's disease. Neurobiol Aging 2006;27:1757-1762.

149. Hanyu H, Asano T, Sakurai H, Takasaki M, Shindo H, Abe K. Magnetization transfer measurements of the hippocampus in the early diagnosis of Alzheimer's disease. J Neurol Sci 2001;188: 79-84.

150. Hanyu H, Shimizu S, Tanaka Y, Kanetaka H, Iwamoto T, Abe K. Differences in magnetization transfer ratios of the hippocampus between dementia with Lewy bodies and Alzheimer's disease. Neurosci Lett 2005;380:166-169.

151. Mascalchi M, Lolli F, Della Nave R, et al. Huntington disease: volumetric, diffusion-weighted, and magnetization transfer MR imaging of brain. Radiology 2004;232:867-873.

152. Hanyu H, Asano T, Sakurai H, Takasaki M, Shindo H, Abe K. Magnetisation transfer measurements of the subcortical grey and white matter in Parkinson's disease with and without dementia and in progressive supranuclear palsy. Neuroradiology 2001;43: $542-546$.

153. Tambasco N, Pelliccioli GP, Chiarini P, et al. Magnetization transfer changes of grey and white matter in Parkinson's disease. Neuroradiology 2003;45:224-230.

154. Eckert T, Sailer M, Kaufmann J, et al. Differentiation of idiopathic Parkinson's disease, multiple system atrophy, progressive supranuclear palsy, and healthy controls using magnetization transfer imaging. Neuroimage 2004;21:229-235.

155. Anik Y, Iseri P, Demirci A, Komsuoglu S, Inan N. Magnetization transfer ratio in early period of Parkinson disease. Acad Radiol 2007;14:189-192.

156. Naka H, Imon Y, Ohshita T, et al. Magnetization transfer measurements of brain structures in patients with multiple system atrophy. Neuroimage 2002;17:1572-1578.

157. Kato Y, Matsumura K, Kinosada Y, Narita Y, Kuzuhara S, Nakagawa $\mathrm{T}$. Detection of pyramidal tract lesions in amyotrophic lateral sclerosis with magnetization-transfer measurements. AJNR Am J Neuroradiol 1997;18:1541-1547.

158. Tanabe JL, Vermathen M, Miller R, Gelinas D, Weiner MW, Rooney WD. Reduced MTR in the corticospinal tract and normal T2 in amyotrophic lateral sclerosis. Magn Reson Imaging 1998; 16:1163-1169.

159. Ferini Strambi L, Bozzali M, Cercignani M, Oldani A, Zucconi M, Filippi M. Magnetization transfer and diffusion-weighted imaging in nocturnal frontal lobe epilepsy. Neurology 2000;54: 2331-2333.

160. Rugg-Gunn FJ, Eriksson SH, Boulby PA, Symms MR, Barker GJ, Duncan JS. Magnetization transfer imaging in focal epilepsy. Neurology 2003;60:1638-1645.

161. Tofts PS, Sisodiya S, Barker GJ, et al. MR magnetization transfer measurements in temporal lobe epilepsy: a preliminary study. AJNR Am J Neuroradiol 1995;16:1862-1863.

162. Li LM, Narayanan S, Pike GB, Andermann F, Dubeau F, Arnold DL. Magnetization transfer ratio is unable to lateralize epileptic foci in patients with temporal lobe epilepsy. AJNR Am J Neuroradiol 2000;21:1853-1856.

163. Flugel D, Cercignani M, Symms MR, Koepp MJ, Foong J. A magnetization transfer imaging study in patients with temporal lobe epilepsy and interictal psychosis. Biol Psychiatry 2006;59: 560-567.

164. Hahnel S, Freund M, Munkel K, et al. Magnetisation transfer ratio is low in normal-appearing cerebral white matter in patients with normal pressure hydrocephalus. Neuroradiology 2000;42:174179.

165. Hahnel S, Munkel K, Jansen O, et al. Magnetization transfer measurements in normal-appearing cerebral white matter in patients with chronic obstructive hydrocephalus. J Comput Assist Tomogr 1999;23:516-520.

166. Okumura A, Takenaka K, Nishimura Y, et al. The characterization of human brain tumor using magnetization transfer technique in magnetic resonance imaging. Neurol Res 1999;21:250-254.

167. Peretti-Viton P, Taieb D, Viton JM, et al. Contrast-enhanced magnetisation transfer MRI in metastatic lesions of the brain. Neuroradiology 1998;40:783-787.

168. Thng CH, Tay KH, Chan LL, et al. Magnetic resonance imaging of brain metastases: magnetisation transfer or triple dose gadolinium? Ann Acad Med Singapore 1999;28:529-533.

169. Zikou A, Ioannidou MC, Tzoufi M, Astrakas L, Argyropoulou MI. Magnetization transfer ratio measurements of the brain in children with tuberous sclerosis complex. Pediatr Radiol 2005; 35:1071-1074.

170. Pinto Gama HP, da Rocha AJ, Braga FT, et al. Comparative analysis of MR sequences to detect structural brain lesions in tuberous sclerosis. Pediatr Radiol 2006;36:119-125.

171. Argyropoulou MI, Kiortsis DN, Metafratzi Z, Efremidis SC. Magnetisation transfer imaging of the normal adenohypophysis: the effect of sex and age. Neuroradiology 2001;43:305-308.

172. Argyropoulou MI, Kiortsis DN. Magnetization transfer imaging of the pituitary gland. Hormones (Athens) 2003;2:98-102

173. Naka H, Imon Y, Ohshita T, et al. Magnetization transfer measurements of cerebral white matter in patients with myotonic dystrophy. J Neurol Sci 2002;15:111-116.

174. Giorgio A, Dotti MT, Battaglini M, et al. Cortical damage in brains of patients with adult-form of myotonic dystrophy type 1 and no or minimal MRI abnormalities. J Neurol 2006;253:14711477.

175. Antosik-Biernacka A, Peuskens H, De Hert M, et al. Magnetization transfer imaging in chronic schizophrenia. Med Sci Monit 2006;12:MT17-21.

176. Bagary MS, Foong J, Maier M, et al. A magnetization transfer analysis of the thalamus in schizophrenia. J Neuropsychiatry Clin Neurosci 2002;14:443-448.

177. Foong J, Symms MR, Barker GJ, et al. Neuropathological abnormalities in schizophrenia: evidence from magnetization transfer imaging. Brain 2001;124:882-892.

178. Bagary MS, Symms MR, Barker GJ, Mutsatsa SH, Joyce EM, Ron MA. Gray and white matter brain abnormalities in firstepisode schizophrenia inferred from magnetization transfer imaging. Arch Gen Psychiatry 2003;60:779-788.

179. Foong J, Maier M, Barker GJ, Brocklehurst S, Miller DH, Ron MA. In vivo investigation of white matter pathology in schizophrenia with magnetization transfer imaging. J Neurol Neurosurg Psychiatry 2000;68:70-74

180. Kubicki M, Park H, Westin CF, et al. DTI and MTR abnormalities in schizophrenia: analysis of white matter integrity. Neuroimage 2005;26:1109-1118

181. Price G, Cercignani M, Bagary MS, et al. A volumetric MRI and magnetization transfer imaging follow-up study of patients with first-episode schizophrenia. Schizophr Res 2006;87:100-108.

182. Bruno SD, Barker GJ, Cercignani M, Symms M, Ron MA. A study of bipolar disorder using magnetization transfer imaging and voxel-based morphometry. Brain 2004;127:2433-2440.

183. Bruno SD, Papadopoulou K, Cercignani M, Cipolotti L, Ron MA. Structural brain correlates of IQ changes in bipolar disorder. Psychol Med 2006;36:609-618. 